\title{
Analysis of the Financial Chaotic Model with the Fractional Derivative Operator
}

\author{
Mamadou Diouf ${ }^{1}$ and Ndolane Sene $\mathbb{B}^{2}$ \\ ${ }^{1}$ Centre de Recherche Economique Appliqué (CREA)/Laboratoire d'Analyse de Recherche et d'Etude du Développement (LARED), \\ UCAD/FASEG, Dakar, Senegal \\ ${ }^{2}$ Laboratoire Lmdan, Département de Mathématiques de la Décision, Université Cheikh Anta Diop de Dakar, \\ Faculté des Sciences Economiques et Gestion, BP 5683 Dakar Fann, Senegal \\ Correspondence should be addressed to Ndolane Sene; ndolanesene@yahoo.fr
}

Received 26 April 2020; Revised 31 May 2020; Accepted 8 June 2020; Published 29 June 2020

Guest Editor: Karthikeyan Rajagopal

Copyright ( $\odot 2020$ Mamadou Diouf and Ndolane Sene. This is an open access article distributed under the Creative Commons Attribution License, which permits unrestricted use, distribution, and reproduction in any medium, provided the original work is properly cited.

\begin{abstract}
Numerical discretization for the fractional differential equations is applied to the chaotic financial model described by the Caputo derivative. The graphical representations to support the numerical discretization are presented. We profit by analyzing the impact generated by the variations of the saving rate, the per investment cost, and the elasticity of demands in the dynamics of the solutions obtained with our numerical scheme. Notably, we use bifurcation diagrams to quantify the impact of the saving rate, the per investment cost, and the elasticity of demands, as well as the Lyapunov exponent to characterize the existence of chaos for the chosen value of the fractional order. The chaos observed depends strongly on these previously mentioned parameters. We finish by proposing a suitable control to synchronize the drive system and the response fractional financial model, using Lyapunov direct methods. The stability analysis of the equilibrium points of the chaotic financial model has been presented.
\end{abstract}

\section{Introduction}

The debate related to the savings and saving rate, the investment and the investment rate, and demands and the elasticity of demands continues to aliment the literature reviews and researches in economics, finance, and mathematics. We make discussions related to these parameters in the economy and finance before going further. In macroeconomic literature, the determinants of the savings are not the same as those of investments. Savings depend mainly on income and wealth, while investment depends on profitability and risky [1]. However, although savings and investment result from two independent decisions, they are necessarily the same in a closed economy [2,3]. Savings are not necessarily used for domestic investment. They can be invested in the exterior of a country. In the case of capital mobility, the savings of each country will go to the part of the world which offers the highest rate of return [4]. Hence, an increase in national savings will mainly affect a large current account surplus or simply reduce the deficit rather than an increase in domestic investment and economic growth. In classical macroeconomics, the growth of production depends first on investment, which in turn depends on the savings rate. In this case, the interaction between demand and supplying funds determines the level of investment. Note that the investment demand is a negative function according to the real interest rate. The savings are a positive function according to the interest rate. As a result, a shift to the right of the investment demand function will generate an increase in investment rates and an increase in the equilibrium of investment and savings. The investigations between the investment and the savings are reported in many papers; in Turgot [5] and in Benston and Smith [6], savings are considered as automatically devoted to the financing of investment.

Following the literature, the savings can be considered as a source of instability for demand. The Keynesian and Neo-Keynesian and their macroeconomic models, 
contrary to the neoclassical ones, attribute a passive role to savings. According to Keynesian and Neo-Keynesian, economic growth is explained by the investments. For them, the savings stop economic growth because it generates a demand deficit. Thus the investment is privileged to reduce the demand deficit and induce economic growth and more savings. In [7], Keynes emphasizes the links between the amount of investment and the volume of employment. In [8], Domar considers the growth model, where he explains that maintaining full employment requires growth in investment. All Keynesian and NeoKeynesian theoretical models highlight the impact of savings in the process of economic growth and, in particular, the link it maintains with investment and demand. The investigations were related to the empirical developments on the savings and investment rate. In these directions, Feldstein and Stock in [9] prove empirically the holders of capital prefer to keep savings in their country to protect themselves against currency risk and political risk. Thus, the national savings stay in their country, and the domestic investment increases. Obsefeld in [10] stipulates in a base empirical study that, for a large open economy like that of the United States, domestic savings and investment could go together, even if the international capital market worked perfectly. However, it is not justified to consider a strong correlation between savings and investment, implying low capital mobility as announced by Feldstein and Stock in [9]. For more empirical investigations, see Tobin in [11], Dramani et Laye in [12], Esso et Keho in [13], Dries and Pepermans [14], and so forth. At last, the elasticity of demand measures the reaction of buyers to the changes in market conditions. It permits analyzing the variation in the demand with greater precision [15]. Thus, the elasticity of demand is a concept that measures the degree of sensitivity of demand to price (price elasticity) or income ("income elasticity") variations. Among the determinants of demand, we can cite price, income, product quality, and tastes, or preferences.

We note in the literature many discussions related to the concepts of savings, saving rate, investment, investment rate, investment of demand, and the elasticity of demand, permitting opening the door for new applications. In this paper, we focus on these concepts in the context of the financial model taking into account all these concepts. We mainly focus on the chaotic financial model in the context of fractional calculus. We propose a new numerical scheme and depict the solutions according to this numerical scheme and analyze as well the impact of the saving rate, the per investment cost, and the elasticity of demands. There exist investigations related to the fractional financial models. In [16], Shahiri et al. propose the stability and the synchronization of the fractional financial chaotic model. In [17], $\mathrm{Xin}$ and Li introduce a new fractional for order financial chaotic model, propose the numerical schemes using Adam's Bashford method, and illustrate their results with graphical representations. In [18], Chen et al. present the financial 3D chaotic model and introduce the financial 4D chaotic model and propose feedback control to stabilize the chaotic model. In [19], Gao and Ma present the Hopf bifurcation of the chaotic financial model with time delay. In [20], Kumar and Kumar present a new financial chaotic model and also propose the stability analysis of the introduced model using the Lyapunov direct method. In [21], Xu and $\mathrm{He}$ investigate the synchronization of the fractional 3D financial model using an active control method. In [22], Wang et al. propose the fractional financial chaotic model with a different order of the fractional derivative. For many other investigations on chaotic systems, refer to [23-25].

Our motivation and novelty are to propose a new numerical scheme based on the solution of the fractional differential equations. Our numerical schemes will open new doors in numerical methods in fractional calculus and in finance, where the mathematical models are preferred to analyze the behavior of the financial markets. This new paper contributes to the applications of fractional derivatives in finance and economics. Note that there exist many applications of fractional derivatives [26-29] in physics $[27,30,31]$, science and engineering $[27,32]$, mathematical modeling [27, 33], and others fields [26, 34-36]. The context of the fractional derivative is considered in our paper because the memory effect of the dynamical systems is taken into account, which is important for economics and financial models.

In Part 2, we recall the fractional tools. In Part 3, we present the fractional financial chaotic model. In Part 4, we give the qualitative properties like the existence and the uniqueness of the solution of the proposed model. In Part 5, we introduce our new numerical discretization. In Part 6, we give numerical simulations and interpretations. In Part 7, we propose synchronization investigations. In Part 8, we finish with concluding remarks.

\section{Basic Fractional Calculus Operators}

We recall the tools related to the fractional calculus. We address in this section the fractional Caputo derivative, the fractional Riemann-Liouville derivative, and their associated integral. We give the following definitions.

Definition 1 (see $[27,29])$. Consider the function $x:[0,+\infty[\longrightarrow \mathbb{R}$; the fractional derivative in sense of Riemann-Liouville, of order $\alpha$, is represented by the relationship

$$
D^{\alpha} x(t)=\frac{1}{\Gamma(1-\alpha)} \frac{\mathrm{d}}{\mathrm{d} t} \int_{0}^{t} x(s)(t-s)^{-\alpha} \mathrm{d} s,
$$

with the relation

$$
\frac{\mathrm{d} x(t)}{\mathrm{d} t}=\lim _{h \rightarrow 0} \frac{x(t+h)-x(t)}{h},
$$

where $t>0$ and the order $\alpha \in(0,1)$ and $\Gamma(\ldots)$ is the gamma Euler function.

Definition 2 (see [27, 29]). Consider the function $x:[0,+\infty[\longrightarrow \mathbb{R}$; the fractional derivative in sense of Caputo, of order $\alpha$, is represented by the relationship 


$$
D_{c}^{\alpha} x(t)=\frac{1}{\Gamma(1-\alpha)} \int_{0}^{t} \frac{\mathrm{d} x}{\mathrm{~d} s}(t-s)^{-\alpha} \mathrm{d} s,
$$

with the relation

$$
\frac{\mathrm{d} x(t)}{\mathrm{d} t}=\lim _{h \longrightarrow 0} \frac{x(t+h)-x(t)}{h},
$$

where $t>0$ and the order $\alpha \in(0,1)$ and $\Gamma(\ldots)$ is the gamma Euler function.

Definition 3 (see [27, 29]). The Riemann-Liouville fractional integral is represented as the following form for the function $x:[0,+\infty[\longrightarrow \mathbb{R}:$

$$
\left(I^{\alpha} x\right)(t)=\frac{1}{\Gamma(\alpha)} \int_{0}^{t}(t-s)^{\alpha-1} x(s) \mathrm{d} s,
$$

where the function $\Gamma(\ldots)$ represents the Gamma Euler function with the order $\alpha>0$.

\section{Fractional Financial Chaotic Model}

In this section, we present the chaotic model used in finance and economy in the context of fractional time order derivative. The chaotic financial model considered in our works can be represented with the integer-order derivative as the following form:

$$
\begin{gathered}
\partial_{t} x=z+y x-a x, \\
\partial_{t} y=1-b y-x^{2}, \\
\partial_{t} z=-x-c z,
\end{gathered}
$$

with the initial conditions defined by the following equations:

$$
\begin{aligned}
& x(0)=x_{0}, \\
& y(0)=y_{0}, \\
& z(0)=z_{0},
\end{aligned}
$$

where the variable $x$ represents the interest rate, $y$ denotes the investment demand, and the variable $z$ denotes the price exponent. The parameter $a$ means the saving rate; the parameter $b$ represents the per investment cost; the parameter $c$ indicates the elasticity of demands. The generalization of the dynamical system described by equations (6)-(8) can be done using the fractional-order derivative due to the memory effect. In other words, the deterministic of the dynamical systems is, in general, well modeled by the fractional-order derivative. Therefore, in this paper, we consider the fractional-order derivative to model the chaotic financial model. The chaotic model is known to be very sensitive to the initial condition; this point will be focused more on an understanding of the financial market. In other words, to understand more precisely the evolutions of the interest rate, the investment demand, and the price exponent, the following equations represent the fractional financial chaotic model considered in this paper:

$$
\begin{aligned}
& D_{c}^{\alpha} x=z+y x-a x, \\
& D_{c}^{\alpha} y=1-b y-x^{2}, \\
& D_{c}^{\alpha} z=-x-c z .
\end{aligned}
$$

We make the following assumptions related to the initial conditions:

$$
\begin{aligned}
& x(0)=x_{0}, \\
& y(0)=y_{0}, \\
& z(0)=z_{0} .
\end{aligned}
$$

\section{Qualitative Properties of the Fractional Model}

In this section, we prove that the fractional financial chaotic model represented by equations (10)-(12) has unique solution. We consider the following function:

$$
\phi(t, x)=z+y x-a x .
$$

The Lipschitz continuous condition and the Lipchitz constant are provided in the following reasoning. We assume that $x, y$, and $z$ are all bounded. We have

$$
\begin{aligned}
\left\|\phi\left(t, x_{1}\right)-\phi\left(t, x_{2}\right)\right\| & =\left\|z+y x_{1}-a x_{1}-z-y x_{2}+a x_{2}\right\| \\
& \leq\|y\|\left\|x_{1}-x_{2}\right\|+a\left\|x_{1}-x_{2}\right\| \\
& \leq[a+\epsilon]\left\|x_{1}-x_{2}\right\|,
\end{aligned}
$$

where, according to the assumptions, we have $\|y\| \leq \epsilon$.

Using the function $\phi$, we construct a Picard's operator using the fractional integral; we have the following equation:

$$
\Delta x=x(0)+I^{\alpha} \phi(t, x) .
$$

We prove that the operator $\Delta$ is bounded. We adopt the following reasoning. We apply the Euclidean norm; that is,

$$
\begin{aligned}
\|\Delta x-x(0)\| & =\left\|I^{\alpha} \phi(t, x)\right\| \\
& \leq\|\phi\| I^{\alpha}(1) \\
& \leq\left[\frac{T^{\alpha}}{\Gamma(\alpha+1)}\right]\|\phi\| .
\end{aligned}
$$

Equation (15) proves $\phi$ is Lipschitz continuous, which implies, in particular, that the function $\phi$ is bounded; that is, $\|\phi\| \leq \epsilon_{1}$. By substituting in equation (17), we obtain the equation defined by

$$
\|\Delta x-x(0)\| \leq\left[\frac{T^{\alpha}}{\Gamma(\alpha+1)}\right] \epsilon_{1} .
$$

We now provided a condition under which the operator $\Delta$ is a contraction. We adopt the following procedure to provide this condition: 


$$
\begin{aligned}
\left\|\Delta x_{1}-\Delta x_{2}\right\| & =\left\|I^{\alpha}\left[\phi\left(t, x_{1}\right)-\phi\left(t, x_{2}\right)\right]\right\| \\
& \leq I^{\alpha}\left\|\phi\left(t, x_{1}\right)-\phi\left(t, x_{2}\right)\right\| \\
& \leq\left\|\phi\left(t, x_{1}\right)-\phi\left(t, x_{2}\right)\right\| I^{\alpha}(1) \\
& \leq\left[\frac{T^{\alpha}}{\Gamma(\alpha+1)}\right][a+\epsilon]\left\|x_{1}-x_{2}\right\| .
\end{aligned}
$$

That is, Picard's operator is a contraction when the relation is defined by

$$
\frac{T^{\alpha}}{\Gamma(\alpha+1)} \leq \frac{1}{a+\epsilon}
$$

which in turn implies that, under Banach fixed theorem, the solution of the fractional differential equation described by equation (10) exists and is unique. The uniqueness of the solution can be established using the following reasoning. We suppose two different solutions $x_{1}$ and $x_{2}$ for the fractional differential equation defined by equation (10). We suppose the following relationship is held:

$$
\begin{aligned}
& x_{1}(t)=x_{1}(0)+I^{\alpha} \phi\left(t, x_{1}\right), \\
& x_{2}(t)=x_{2}(0)+I^{\alpha} \phi\left(t, x_{1}\right) .
\end{aligned}
$$

The difference between equations (21) and (22) yields

$$
x_{1}(t)-x_{2}(t)=I^{\alpha}\left[\phi\left(t, x_{1}\right)-\phi\left(t, x_{2}\right)\right] .
$$

Applying the norm to equation (23), we get the following relationships:

$$
\begin{aligned}
\left\|x_{1}-x_{2}\right\| & =\left\|I^{\alpha}\left[\phi\left(t, x_{1}\right)-\phi\left(t, x_{2}\right)\right]\right\| \\
& \leq I^{\alpha}\left\|\phi\left(t, x_{1}\right)-\phi\left(t, x_{2}\right)\right\| \\
& \leq\left\|\phi\left(t, x_{1}\right)-\phi\left(t, x_{2}\right)\right\| I^{\alpha}(1) \\
& \leq\left[\frac{T^{\alpha}}{\Gamma(\alpha+1)}\right][a+\epsilon]\left\|x_{1}-x_{2}\right\| .
\end{aligned}
$$

From them, we have the following equation:

$$
\left\|x_{1}-x_{2}\right\|\left[1-\left[\frac{T^{\alpha}}{\Gamma(\alpha+1)}\right][a+\epsilon]\right] \leq 0 .
$$

That implies $\left\|x_{1}-x_{2}\right\| \leq 0$. Furthermore, we know by definition of the Euclidean norm $\left\|x_{1}-x_{2}\right\| \geq 0$. Thus, we conclude that the following equation is held; that is,

$$
x_{1}=x_{2} \text {. }
$$

The solution of equation (10) is unique. We conclude that the first equation of the financial chaotic model has a solution and this solution is unique.

In the second step, we consider the following function in our procedure:

$$
\varphi(t, y)=1-b y-x^{2}
$$

We adopt the previous procedure by providing the Lipschitz continuous condition and the Lipschitz constant for the function $\varphi$. We assume that $x, y$, and $z$ are bounded. We have the following relation:

$$
\begin{aligned}
\left\|\varphi\left(t, y_{1}\right)-\varphi\left(t, y_{2}\right)\right\| & =\left\|1-b y_{1}-x^{2}-1+b y_{2}+x^{2}\right\| \\
& \leq b\left\|y_{1}-y_{2}\right\| .
\end{aligned}
$$

Using the function $\varphi$, we construct a Picard's operator using the fractional integral; we have the following equation:

$$
\Omega y=y(0)+I^{\alpha} \varphi(t, y) .
$$

We prove the operator $\Omega$ is bounded. We adopt the following reasoning. We apply the Euclidean norm; that is,

$$
\begin{aligned}
\|\Omega y-y(0)\| & =\left\|I^{\alpha} \varphi(t, y)\right\| \\
& \leq\|\varphi\| I^{\alpha}(1) \\
& \leq\left[\frac{T^{\alpha}}{\Gamma(\alpha+1)}\right]\|\varphi\| .
\end{aligned}
$$

Equation (28) proves $\varphi$ is Lipchitz continuous, which implies, in particular, that the function $\varphi$ is bounded, that is, $\|\varphi\| \leq \epsilon_{2}$. Replacing into equation (30), we obtain the equation defined by

$$
\|\Omega y-y(0)\| \leq\left[\frac{T^{\alpha}}{\Gamma(\alpha+1)}\right] \epsilon_{2} .
$$

We now provided a condition under which the operator $\Omega$ is a contraction. We adopt the following procedure to provide this condition:

$$
\begin{aligned}
\left\|\Omega y_{1}-\Omega y_{2}\right\| & =\left\|I^{\alpha}\left[\varphi\left(t, y_{1}\right)-\varphi\left(t, y_{2}\right)\right]\right\| \\
& \leq I^{\alpha}\left\|\varphi\left(t, y_{1}\right)-\varphi\left(t, y_{2}\right)\right\| \\
& \leq\left\|\varphi\left(t, y_{1}\right)-\varphi\left(t, y_{2}\right)\right\| I^{\alpha}(1) \\
& \leq\left[\frac{T^{\alpha}}{\Gamma(\alpha+1)}\right] b\left\|y_{1}-y_{2}\right\| .
\end{aligned}
$$

That is, Picard's operator $\Omega$ is a contraction when the relation defined by

$$
\frac{T^{\alpha}}{\Gamma(\alpha+1)} \leq \frac{1}{b},
$$

is held, which in turn implies that, under Banach fixed theorem, the solution of the fractional differential equation described by equation (11) exists and is unique. The uniqueness of the solution can be established using the following reasoning. We suppose different solutions $y_{1}$ and $y_{2}$ for the fractional differential equation defined by equation (11). That is, the following relationships are held:

$$
\begin{aligned}
& y_{1}(t)=y_{1}(0)+I^{\alpha} \varphi\left(t, y_{1}\right), \\
& y_{2}(t)=y_{2}(0)+I^{\alpha} \varphi\left(t, y_{1}\right) .
\end{aligned}
$$


The difference between equations (34) and (35) yields

$$
y_{1}(t)-y_{2}(t)=I^{\alpha}\left[\varphi\left(t, y_{1}\right)-\varphi\left(t, y_{2}\right)\right] \text {. }
$$

Applying the norm to equation (36), we get the following relationships:

$$
\begin{aligned}
\left\|y_{1}-y_{2}\right\| & =\left\|I^{\alpha}\left[\varphi\left(t, y_{1}\right)-\varphi\left(t, y_{2}\right)\right]\right\| \\
& \leq I^{\alpha}\left\|\varphi\left(t, y_{1}\right)-\varphi\left(t, y_{2}\right)\right\| \\
& \leq\left\|\varphi\left(t, y_{1}\right)-\varphi\left(t, y_{2}\right)\right\| I^{\alpha}(1) \\
& \leq\left[\frac{T^{\alpha}}{\Gamma(\alpha+1)}\right] b\left\|y_{1}-y_{2}\right\| .
\end{aligned}
$$

From them, we have the following equation:

$$
\left\|y_{1}-y_{2}\right\|\left[1-\left[\frac{T^{\alpha}}{\Gamma(\alpha+1)}\right] b\right] \leq 0 .
$$

That implies $\left\|y_{1}-y_{2}\right\| \leq 0$. Furthermore, we know by the definition of the Euclidean norm $\left\|y_{1}-y_{2}\right\| \geq 0$. Thus, we obtain the following equation:

$$
y_{1}=y_{2}
$$

Then the solution of equation (11) is unique. We conclude that the second equation of the financial chaotic model has one solution.

In the third step, we consider the following function in our reasoning:

$$
\psi(t, y)=-x-c z
$$

We adopt the same reasoning as in the first and the second steps. We assume that $x, y$, and $z$ are bounded. We have the following relation:

$$
\begin{aligned}
\left\|\psi\left(t, z_{1}\right)-\psi\left(t, z_{2}\right)\right\| & =\left\|-x-c z_{1}+x+c z_{2}\right\| \\
& \leq c\left\|z_{1}-z_{2}\right\| .
\end{aligned}
$$

Using the function $\psi$, we construct a Picard's operator using the fractional integral; we have the following equation:

$$
\Lambda z=z(0)+I^{\alpha} \psi(t, z) .
$$

We prove the operator $\Lambda$ is bounded. We adopt the following reasoning. We apply the Euclidean norm; that is,

$$
\begin{aligned}
\|\Lambda z-z(0)\| & =\left\|I^{\alpha} \psi(t, z)\right\| \\
& \leq\|\psi\| I^{\alpha}(1) \\
& \leq\left[\frac{T^{\alpha}}{\Gamma(\alpha+1)}\right]\|\psi\| .
\end{aligned}
$$

Equation (41) proves $\psi$ is Lipschitz continuous, which implies, in particular, that the function $\psi$ is bounded, that is, $\|\psi\| \leq \epsilon_{3}$. Replacing into equation (43), we obtain the equation defined by

$$
\|\Lambda z-z(0)\| \leq\left[\frac{T^{\alpha}}{\Gamma(\alpha+1)}\right] \epsilon_{3} .
$$

We now provide a condition under which the operator $\Lambda$ is a contraction. We adopt the following procedure to provide this condition:

$$
\begin{aligned}
\left\|\Lambda z_{1}-\Lambda z_{2}\right\| & =\left\|I^{\alpha}\left[\psi\left(t, z_{1}\right)-\varphi\left(t, y_{2}\right)\right]\right\| \\
& \leq I^{\alpha}\left\|\psi\left(t, z_{1}\right)-\psi\left(t, y_{2}\right)\right\| \\
& \leq\left\|\psi\left(t, z_{1}\right)-\psi\left(t, y_{2}\right)\right\| I^{\alpha}(1) \\
& \leq\left[\frac{T^{\alpha}}{\Gamma(\alpha+1)}\right] c\left\|z_{1}-z_{2}\right\| .
\end{aligned}
$$

That is, Picard's operator $\Lambda$ is a contraction when the relation defined by

$$
\frac{T^{\alpha}}{\Gamma(\alpha+1)} \leq \frac{1}{c}
$$

is held, which in turn implies that, under Banach fixed theorem, the solution of the fractional differential equation described by equation (12) exists and is unique. The uniqueness of the solution can be established using the following reasoning. We suppose different solutions $z_{1}$ and $z_{2}$ for the fractional differential equation defined by equation (12). That is, the following relationships are held:

$$
\begin{aligned}
& z_{1}(t)=z_{1}(0)+I^{\alpha} \psi\left(t, z_{1}\right), \\
& z_{2}(t)=z_{2}(0)+I^{\alpha} \psi\left(t, z_{1}\right) .
\end{aligned}
$$

The difference between equations (47) and (48) yields

$$
z_{1}(t)-z_{2}(t)=I^{\alpha}\left[\psi\left(t, z_{1}\right)-\psi\left(t, z_{2}\right)\right] .
$$

Applying the norm to equation (49), we get the following relationships:

$$
\begin{aligned}
\left\|z_{1}-z_{2}\right\| & =\left\|I^{\alpha}\left[\psi\left(t, z_{1}\right)-\psi\left(t, z_{2}\right)\right]\right\| \\
& \leq I^{\alpha}\left\|\psi\left(t, z_{1}\right)-\psi\left(t, z_{2}\right)\right\| \\
& \leq\left\|\psi\left(t, z_{1}\right)-\psi\left(t, z_{2}\right)\right\| I^{\alpha}(1) \\
& \leq\left[\frac{T^{\alpha}}{\Gamma(\alpha+1)}\right] c\left\|z_{1}-z_{2}\right\| .
\end{aligned}
$$

From them, we have the following equation:

$$
\left\|z_{1}-z_{2}\right\|\left[1-\left[\frac{T^{\alpha}}{\Gamma(\alpha+1)}\right] c\right] \leq 0 .
$$

That implies $\left\|z_{1}-z_{2}\right\| \leq 0$. Furthermore, we know by the definition of the Euclidean norm $\left\|z_{1}-z_{2}\right\| \geq 0$. Thus, we conclude the following equation:

$$
z_{1}=z_{2} \text {. }
$$

That is, the solution of the fractional differential equation (12) is unique. We conclude that the third equation of the financial chaotic model has one solution. 


\section{Discretization Procedures for the Financial Chaotic Model}

In this section, we propose the numerical discretization of the chaotic financial equation with implicit numerical discretization in the context of fractional calculus. The method exposed in this section uses Picard's operator previously defined in this paper. The following relationships give the solutions of the equations of the fractional financial chaotic model (10)-(13) using the Riemann-Liouville integral:

$$
\begin{aligned}
& x(t)=x(0)+I^{\alpha} \phi(t, x), \\
& y(t)=y(0)+I^{\alpha} \varphi(t, y), \\
& z(t)=z(0)+I^{\alpha} \psi(t, z) .
\end{aligned}
$$

The standard discretization at $\left(t_{n}\right)$ in the context of the Caputo derivative is described in the following procedure. In the first step, equations (53)-(55) are written in the following form:

$$
\begin{aligned}
& x\left(t_{n}\right)=x(0)+I^{\alpha} \phi\left(t_{n}, x\right), \\
& y\left(t_{n}\right)=y(0)+I^{\alpha} \varphi\left(t_{n}, y\right), \\
& z\left(t_{n}\right)=z(0)+I^{\alpha} \psi\left(t_{n}, z\right) .
\end{aligned}
$$

The explicit representations when we translate the Riemann-Liouville integral are given by the following forms:

$$
\begin{aligned}
& x\left(t_{n}\right)=x(0)+\frac{1}{\Gamma(\alpha)} \sum_{j=0}^{n} \int_{t_{j}}^{t_{j+1}}\left(t_{n}-s\right)^{\alpha-1} \phi(s, x(s)) \\
& y\left(t_{n}\right)=y(0)+\frac{1}{\Gamma(\alpha)} \sum_{j=0}^{n-1} \int_{t_{j}}^{t_{j+1}}\left(t_{n}-s\right)^{\alpha-1} \varphi(s, t y n(s)), \\
& z\left(t_{n}\right)=z(0)+\frac{1}{\Gamma(\alpha)} \sum_{j=0}^{n-1} \int_{t_{j}}^{t_{j+1}}\left(t_{n}-s\right)^{\alpha-1} \psi(s, z(s)) .
\end{aligned}
$$

We consider the grid $t_{n}=t_{0}+n h$, where $h$ represents a constant step size. Using implicit discretizations of the integral parts of the above equations (57) and (58), we arrive at the following discretizations:

$$
\begin{aligned}
& x\left(t_{n}\right)=x(0)+h^{\alpha}\left[\bar{b}_{n}^{(\alpha)} \varphi(0)+\sum_{j=0}^{n} b_{n-j}^{(\alpha)} \phi\left(t_{j}, x_{j}\right)\right], \\
& y\left(t_{n}\right)=y(0)+h^{\alpha}\left[\bar{b}_{n}^{(\alpha)} \varphi(0)+\sum_{j=0}^{n} b_{n-j}^{(\alpha)} \varphi\left(t_{j}, y_{j}\right)\right], \\
& z\left(t_{n}\right)=z(0)+h^{\alpha}\left[\bar{b}_{n}^{(\alpha)} \varphi(0)+\sum_{j=0}^{n} b_{n-j}^{(\alpha)} \psi\left(t_{j}, z_{j}\right)\right],
\end{aligned}
$$

where the discretization parameters reported in the literature are given by

$$
\bar{b}_{n}^{(\alpha)}=\frac{(n-1)^{\alpha}-n^{\alpha}(n-\alpha-1)}{\Gamma(2+\alpha)},
$$

and, for $n=1,2, \ldots$,

$$
\begin{aligned}
& b_{0}^{(\alpha)}=\frac{1}{\Gamma(2+\alpha)} \\
& b_{n}^{(\alpha)}=\frac{(n-1)^{\alpha+1}-2 n^{\alpha+1}+(n+1)^{\alpha+1}}{\Gamma(2+\alpha)} .
\end{aligned}
$$

Let $x\left(t_{n}\right), y\left(t_{n}\right)$, and $z\left(t_{n}\right)$ be the numerical approximations and let $x_{n}, y_{n}$, and $z_{n}$ be the exact solutions. Then residual functions as reported in the literature of fractional calculus for the implicit numerical discretization are given by the functions

$$
\begin{aligned}
& \left|x\left(t_{n}\right)-x_{n}\right|=\mathcal{O}\left(h^{\min \{\alpha+1,2\}}\right), \\
& \left|y\left(t_{n}\right)-y_{n}\right|=\mathcal{O}\left(h^{\min \{\alpha+1,2\}}\right), \\
& \left|z\left(t_{n}\right)-z_{n}\right|=\mathcal{O}\left(h^{\min \{\alpha+1,2\}}\right) .
\end{aligned}
$$

From them, the convergence of the implicit discretization of equations (10)-(12) is obtained when $h$ converges to 0 . The stability of the numerical discretizations reported in this paper is ensured by the Lipschitz continuous condition of the functions $\phi, \varphi$, and $\psi$. The numerical discretizations of the functions $\phi, \varphi$, and $\psi$ are represented by the equations

$$
\begin{aligned}
& \phi\left(t_{j}, x_{j}\right)=z^{j}+y^{j} x^{j}-a x^{j}, \\
& \varphi\left(t_{j}, y_{j}\right)=1-b y^{j}-\left(x^{j}\right)^{2}, \\
& \psi\left(t_{j}, z_{j}\right)=-x^{j}-c z^{j} .
\end{aligned}
$$

\section{Numerical Simulations and Discussions}

In this section, we simulate the new discretization proposed in the previous section. We fix the following initial conditions: $x(0)=1, y(0)=2$, and $z(0)=0.9$. In the first simulation in Figure 1, we consider $a=0.9, b=0.2, c=1.5$, and the order $\alpha=0.95$. We represent the behavior of the fractional chaotic model in three dimensions. The considered step size is given by $h=0.01$ and $T=1000[s]$.

In Figure 2, we observe the behavior of the solution of the financial chaotic model with respect to the directions $x$ and $z$.

In Figure 3, we observe the behavior of the solution of the financial chaotic model with respect to the directions $x$ and $y$.

We analyze the impact of the saving amount $a$. We represent the dynamics of the fractional financial chaotic model in the following figures with the different values of the saving rate $a=0.1$ seen in Figures $4-6$ and $a=0.2$ seen in Figures 7-9. We notice we have chaotic behaviors when $a$ increases and is approximatively between 0.2 and 1 . But we note high chaotic behaviors when the saving amount is less than approximatively 0.1 . The value of the interest rate can explain the high chaotic behaviors. Note that the savings rate measures, for example, the amount of income of households, businesses, and government savings. To be more precise, the savings rate indicates a nation's health as it shows trends in savings, which lead to investments. The recessions and 


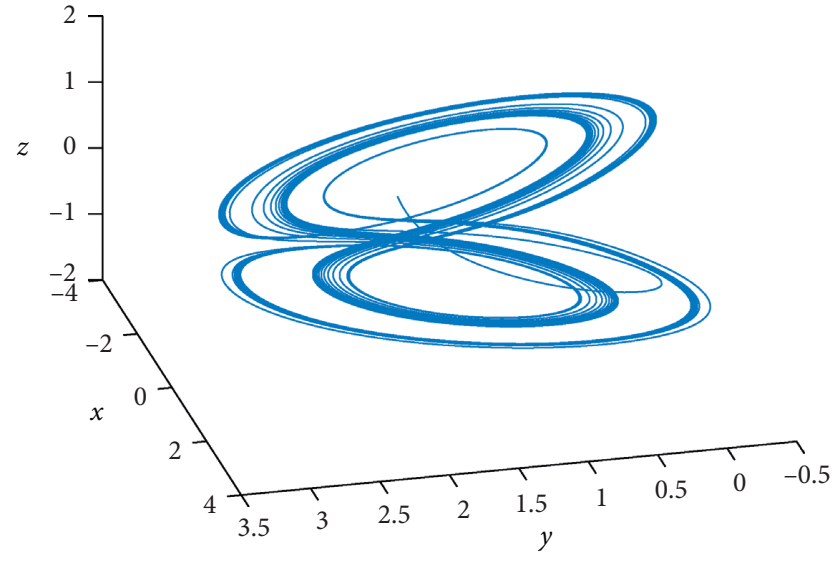

FIgURE 1: Dynamic behavior of fractional financial chaotic model with $\alpha=0.95$.

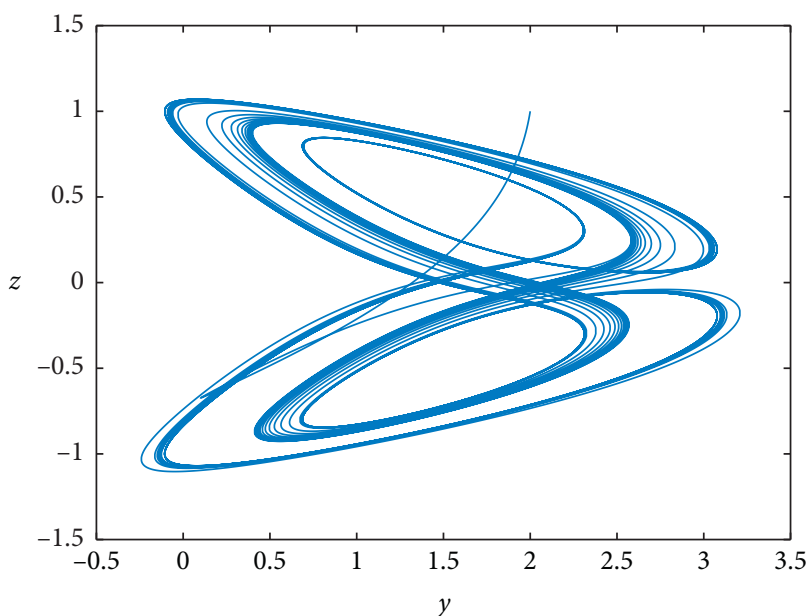

Figure 2: Dynamic behavior of fractional financial chaotic model with $\alpha=0.95$.

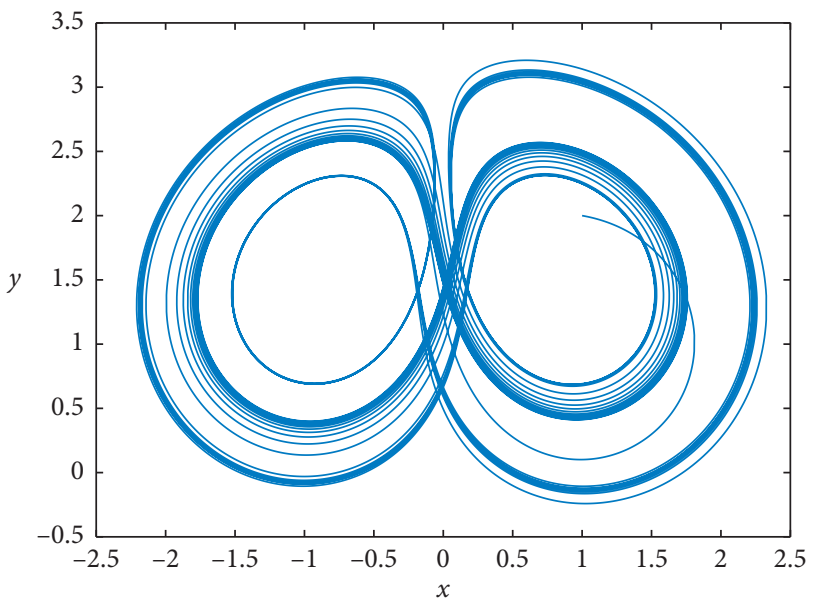

FIGURE 3: Dynamic behavior of fractional financial chaotic model with $\alpha=0.95$.

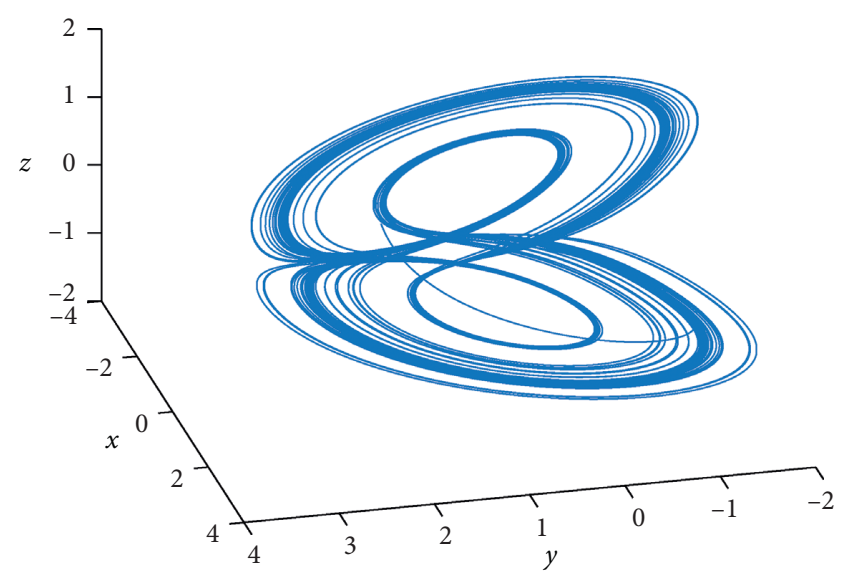

FIGURE 4: Dynamic behavior of fractional financial chaotic model with $\alpha=0.95$.

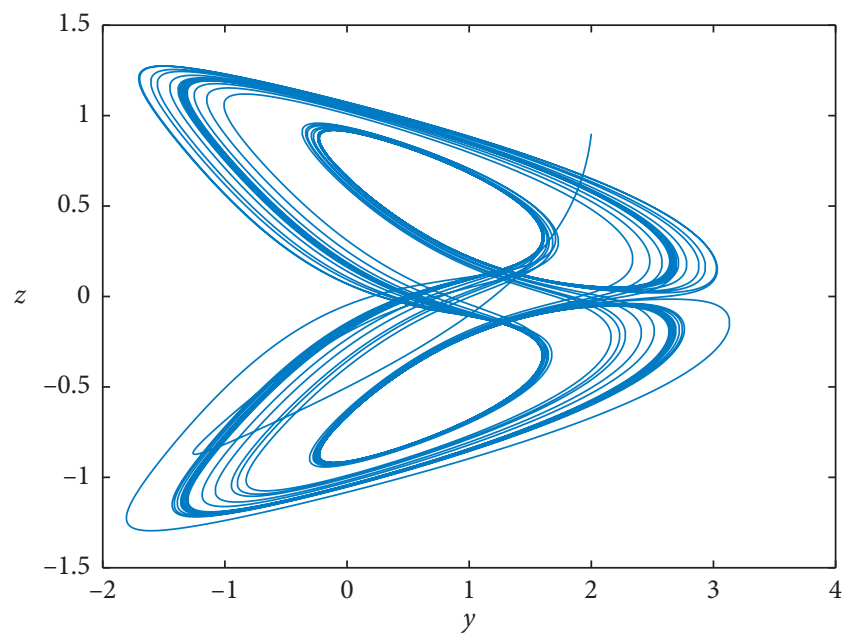

FIGURE 5: Dynamic behavior of fractional financial chaotic model with $\alpha=0.95$.

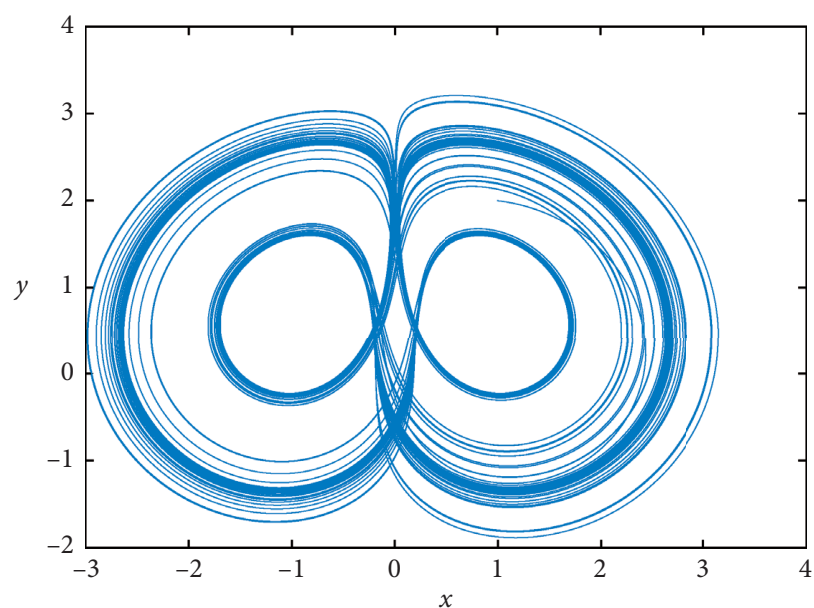

FIGURE 6: Dynamic behavior of fractional financial chaotic model with $\alpha=0.95$. 


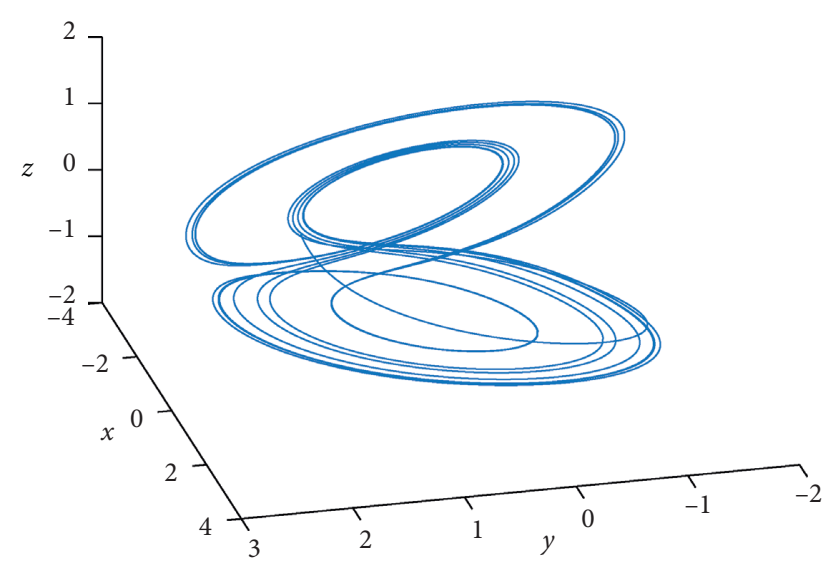

Figure 7: Dynamic behavior of fractional financial chaotic model with $\alpha=0.95$.

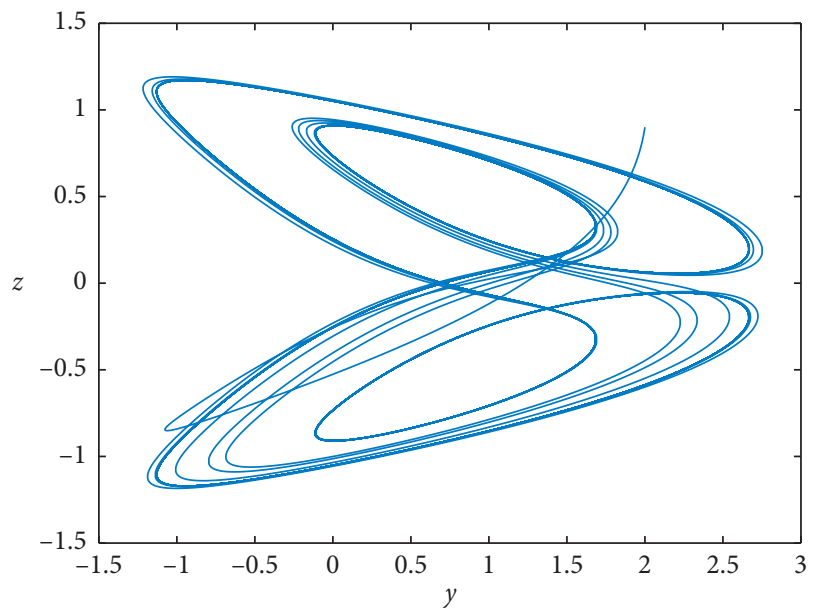

FIGURE 8: Dynamic behavior of fractional financial chaotic model with $\alpha=0.95$.

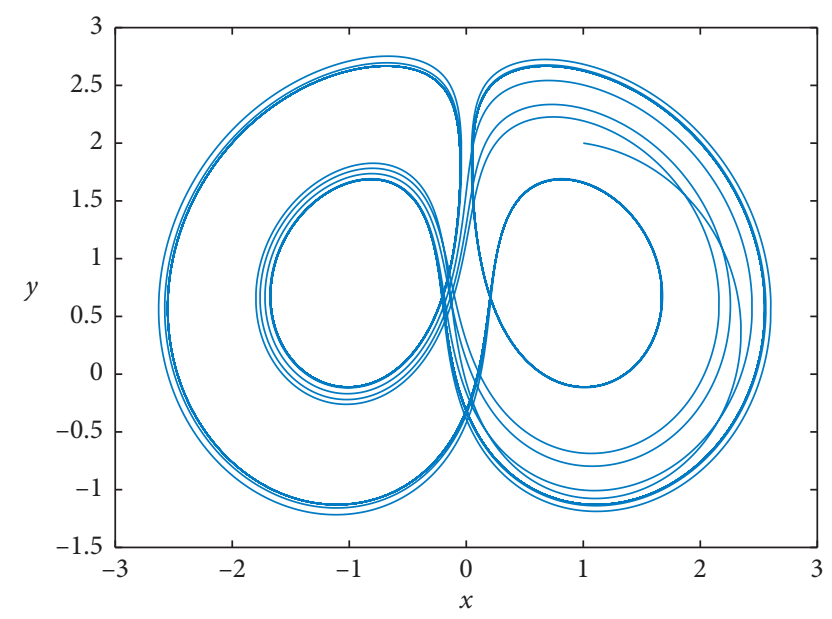

FIgURE 9: Dynamic behavior of fractional financial chaotic model with $\alpha=0.95$. economic shocks impact the saving rate, and in these conditions, we note periods of high economic uncertainty. Thus, people defer current spending to prepare for an uncertain economic future. In our context, when the saving amount is less than approximatively 0.1 , we are in periods of recessions, and the chaotic behavior is high. The future of economic growth becomes difficult to predict. Changes in market interest can also influence the saving rate and thus influence the high chaotic dynamic when the saving amount is less than approximatively 0.1 .

We analyze the impact of the per investment cost $b$. We depict, for more understanding in the following Figures 10-15, the behaviors of the dynamics of the fractional financial chaotic model with $b=0.25$ in Figure 10 and $b=0.4$ in Figure 13. We note the chaotic dynamic is conserved between approximatively 0.2 and 0.3 , but when the per investment cost exceeds 0.4 , the chaotic behavior is displayed. All investments carry costs, real costs, and not merely the opportunity costs of an investor choosing to forego one asset in favor of another. There exist different types of investment costs; thus, different investments carry different types of costs: expensive ratio, marketing costs, and others. More chaotic behaviors are observed in $(0,0.3)$ because in practice when the cost in the investment is not high, it is better for the investors. A high investment cost rate does not generate profit for the investors.

We finish by analyzing the impact of the elasticity of demands $c$. We represent in Figures 16-21 the behavior of the dynamics of the fractional financial chaotic model with $c=1$ in Figure 16 and $c=2$ in Figure 19. We note the chaotic dynamic is conserved between approximately 0 and 2 . Still, when the elasticity of demands exceeds 2 , the chaotic behaviors are displayed, and the solutions of the financial model become stable and describe cycle. Note that elasticity is the degree to which the desire for something changes as its price rises. When $c=0$, we are in case of perfectly inelastic demand, and $c=1$ corresponds to unitary elasticity demand, while $c<1$ corresponds to relatively inelastic demand. We remark for high elasticity with $c<2$; the chaotic behaviors are very high too. Thus the predictions are complicated to be done. But when the elasticity of demands exceeds 2 , then the chaotic behaviors are displayed, and the behaviors can be predicted easily in this case. This phenomenon is not currently in the financial market and is not reasonable in practice.

\section{Synchronization of Fractional Chaotic Financial Model}

In this section, we study the synchronization of the fractional financial model. The objective of synchronization consists of making two chaotic financial models oscillate in the same way. To arrive at our end, we consider two models: the driving system and the response system. All of them are constructed using the fractional financial chaotic model described by equations (10)-(12). Our objective will be to synchronize the driving and the response model using a controller. Therefore a nonlinear fractional system that gives signals between the driving system and the response system 


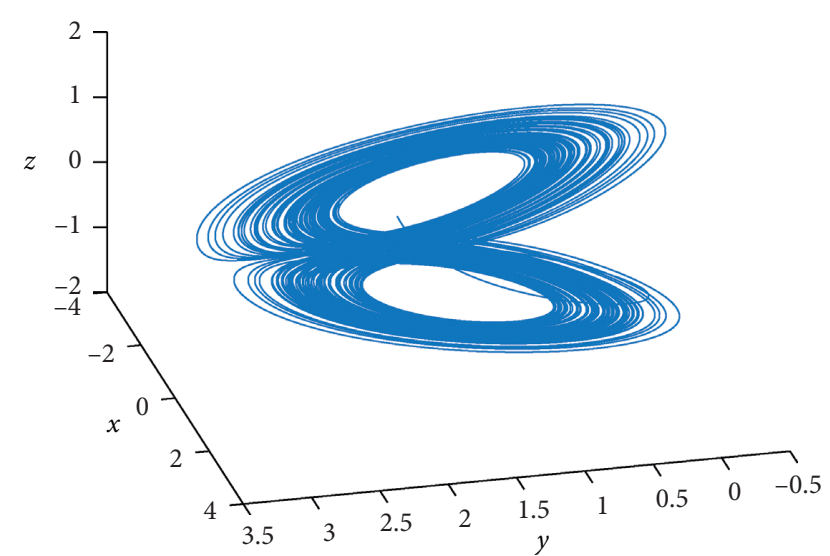

FIgURE 10: Dynamic behavior of fractional financial chaotic model with $\alpha=0.95$.

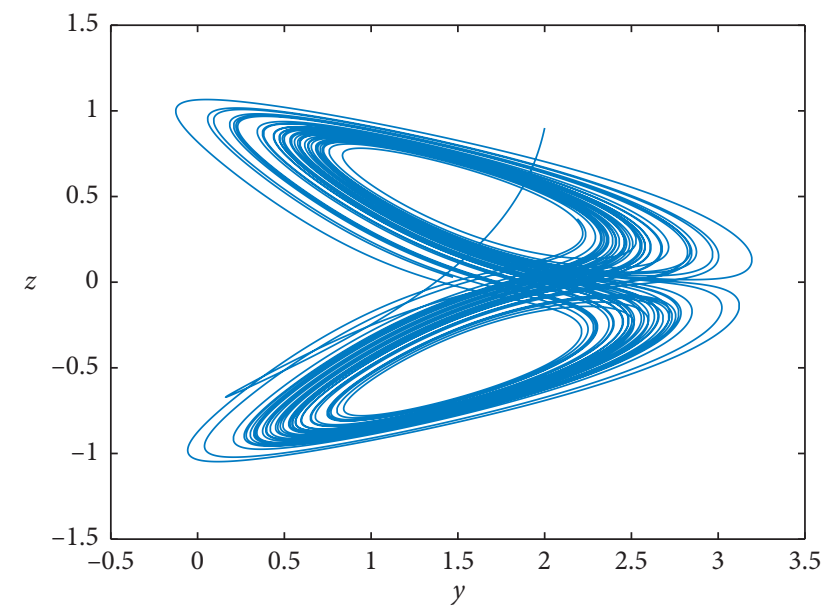

FIGURE 11: Dynamic behavior of fractional financial chaotic model with $\alpha=0.95$.

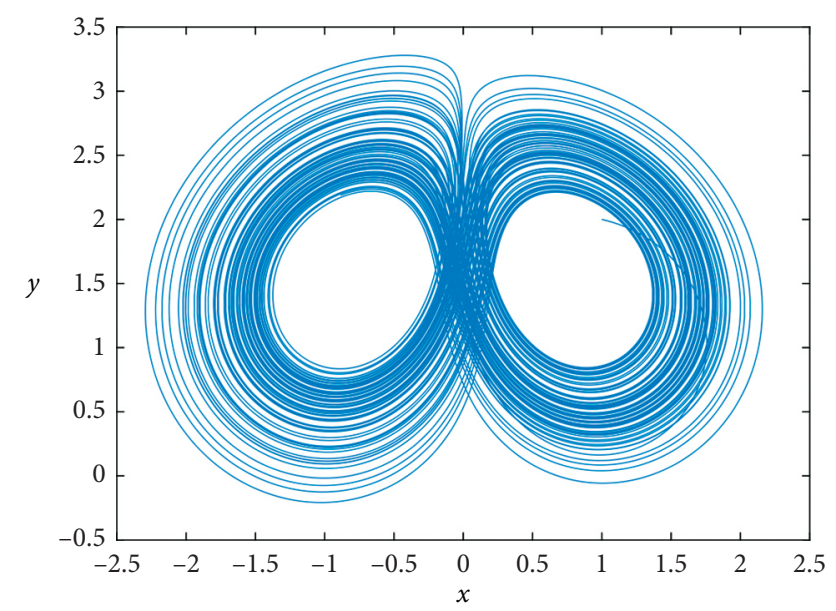

FIGURE 12: Dynamic behavior of fractional financial chaotic model with $\alpha=0.95$.

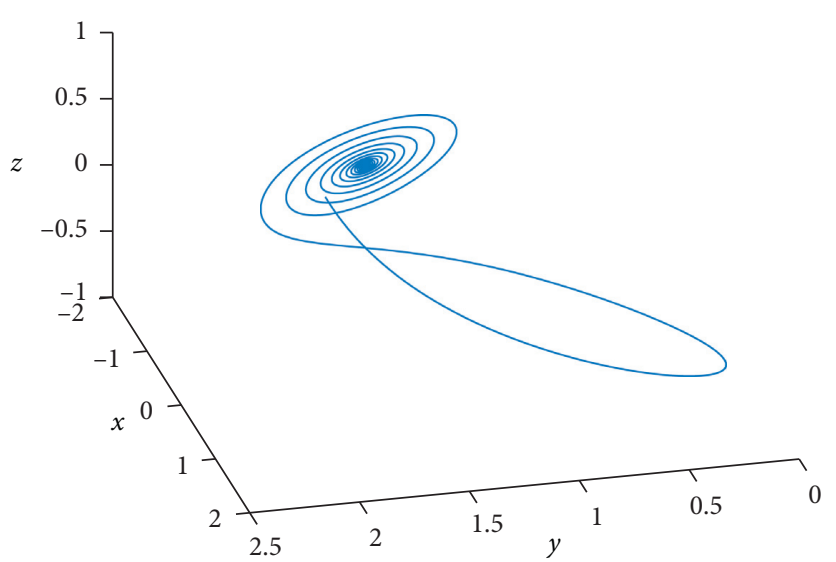

FIGURE 13: Dynamic behavior of fractional financial chaotic model with $\alpha=0.95$.

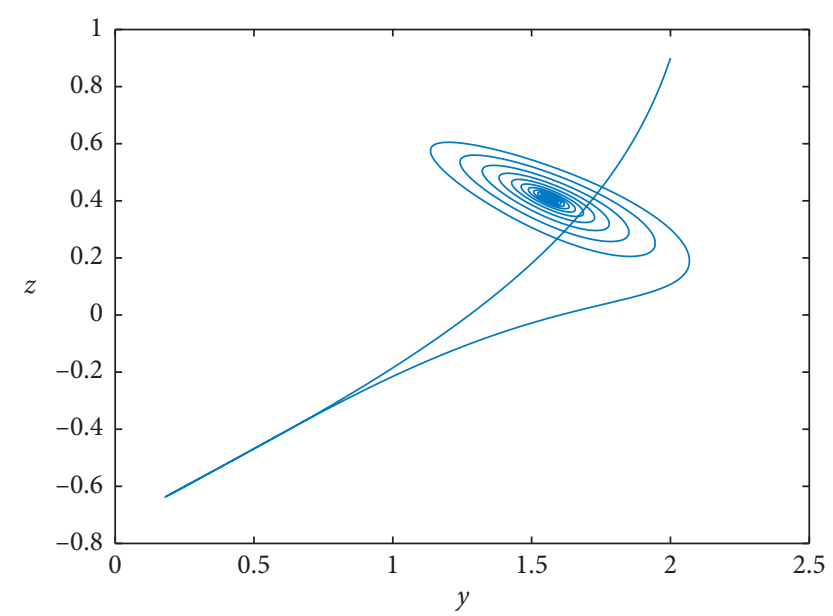

Figure 14: Dynamic behavior of fractional financial chaotic model with $\alpha=0.95$.

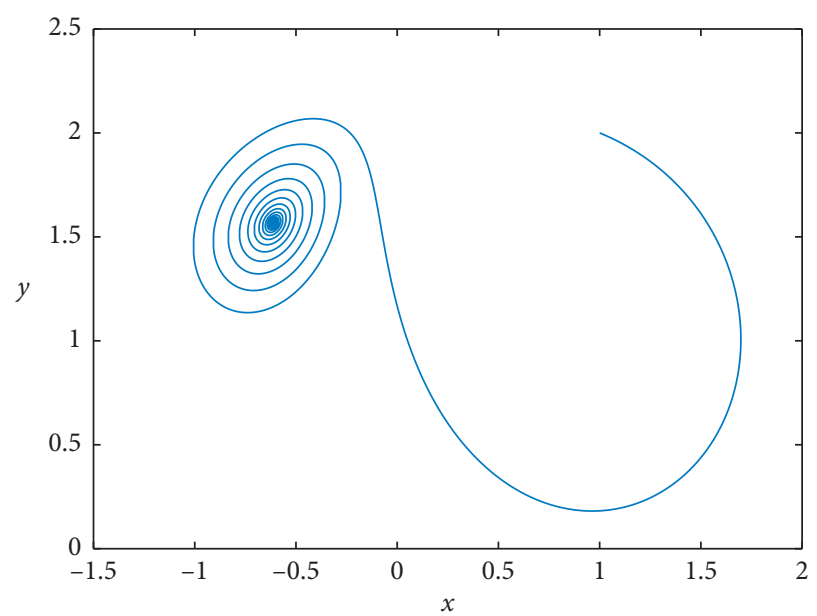

FIGURE 15: Dynamic behavior of fractional financial chaotic model with $\alpha=0.95$. 


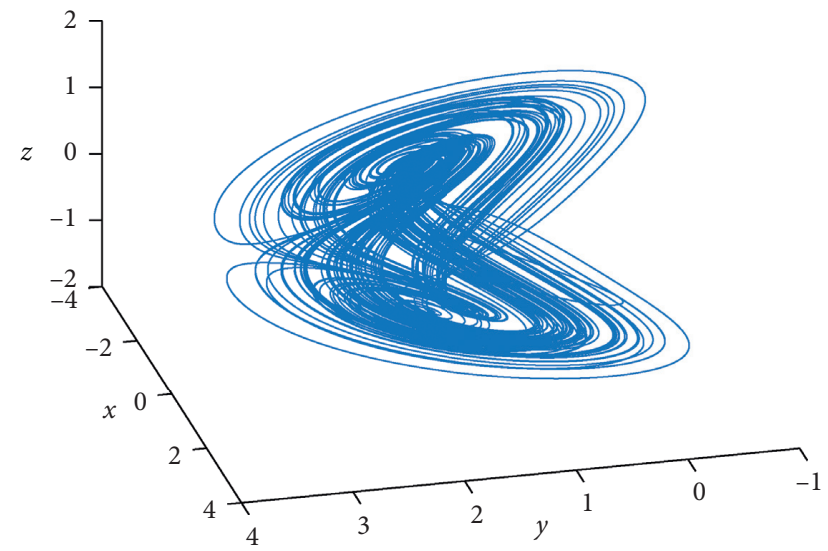

Figure 16: Dynamic behavior of fractional financial chaotic model with $\alpha=0.95$.

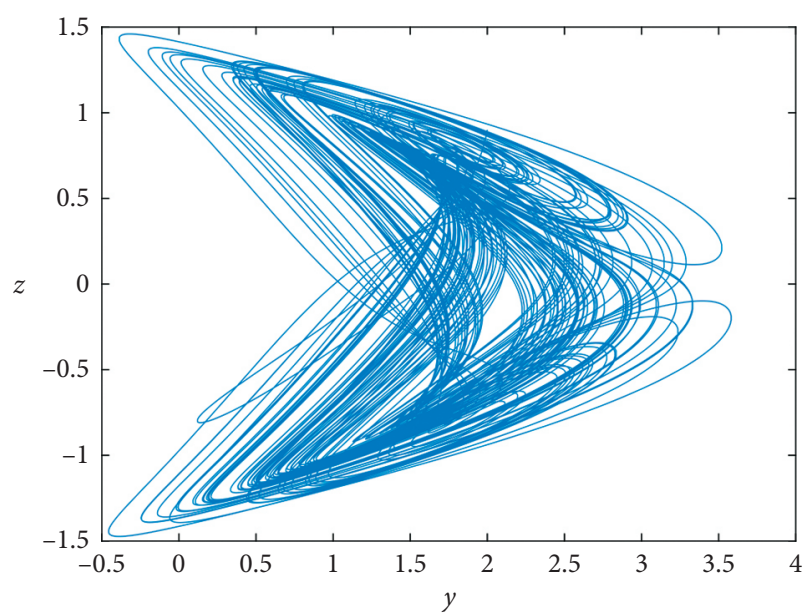

FIGURE 17: Dynamic behavior of fractional financial chaotic model with $\alpha=0.95$.

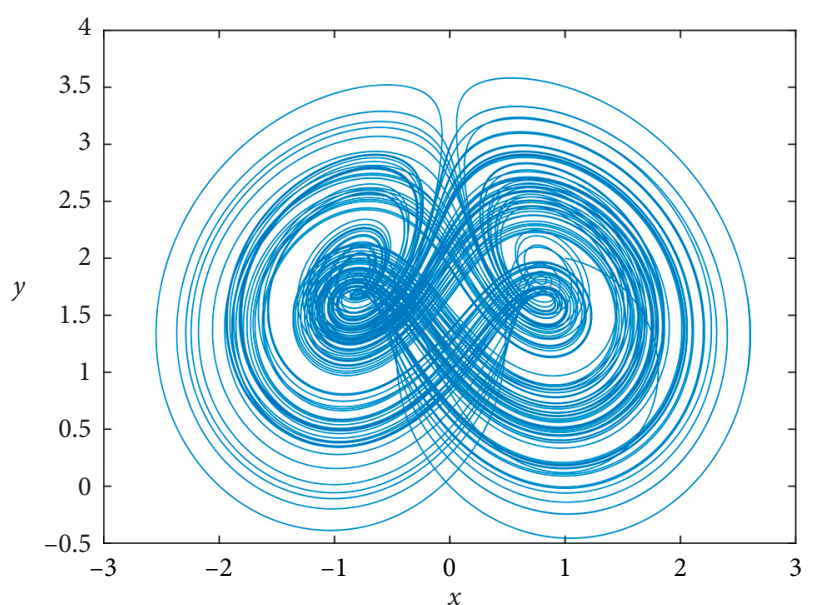

FIGURE 18: Dynamic behavior of fractional financial chaotic model with $\alpha=0.95$.

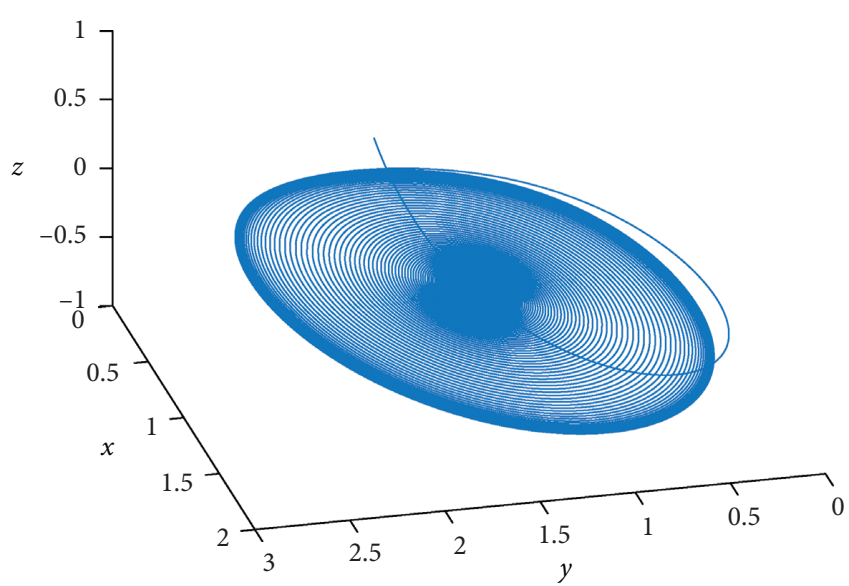

FIGURE 19: Dynamic behavior of fractional financial chaotic model with $\alpha=0.95$.

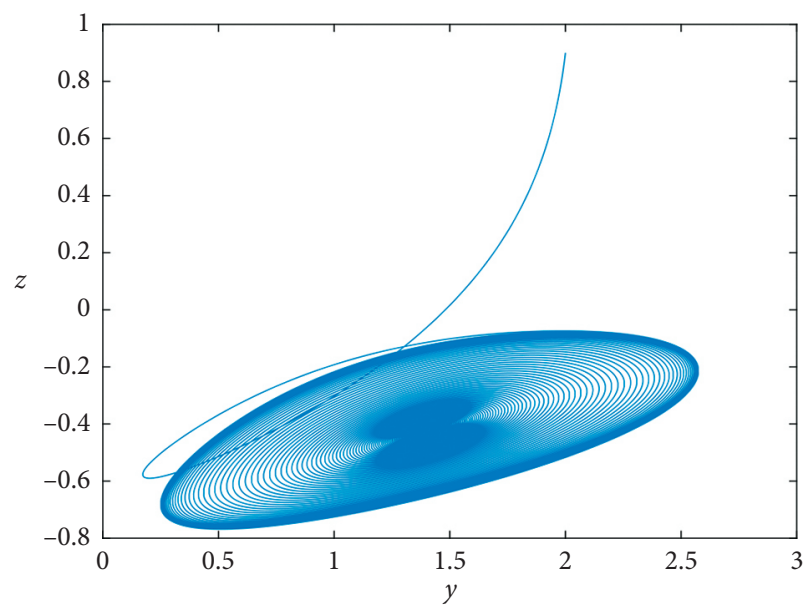

FIgURE 20: Dynamic behavior of fractional financial chaotic model with $\alpha=0.95$.

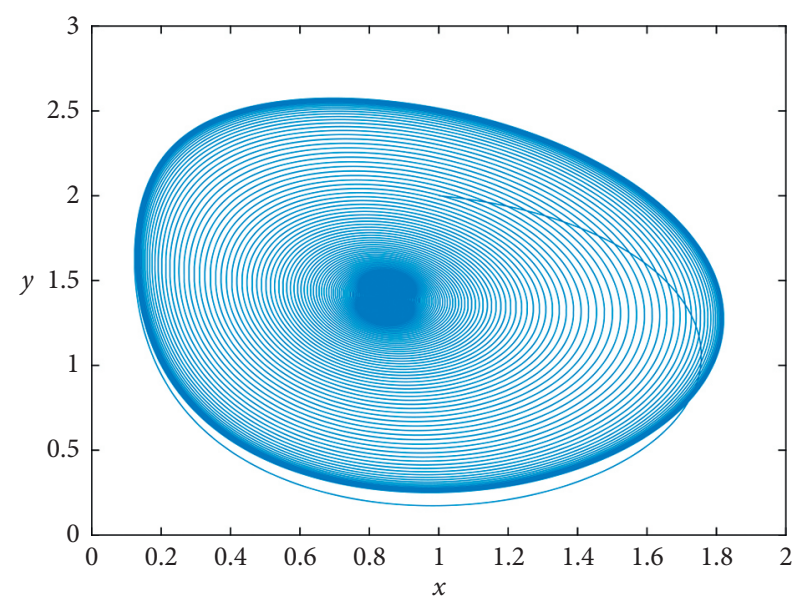

FIgURE 21: Dynamic behavior of fractional financial chaotic model with $\alpha=0.95$. 


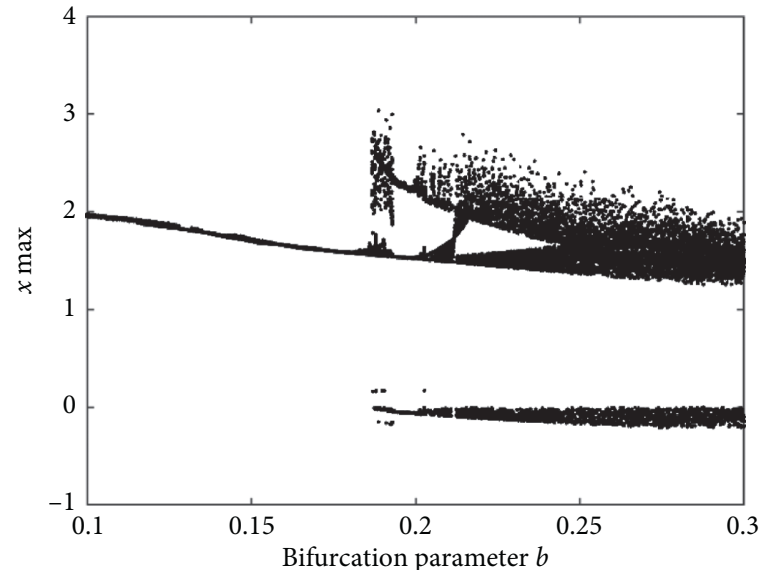

FIgURE 22: Bifurcation diagram with the variation of the parameter $b$.

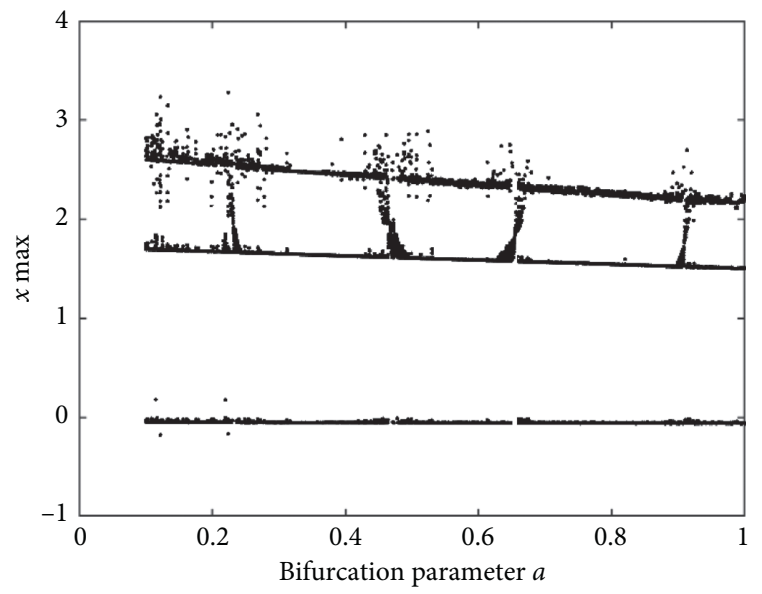

Figure 23: Bifurcation diagram with the variation of the parameter $a$.

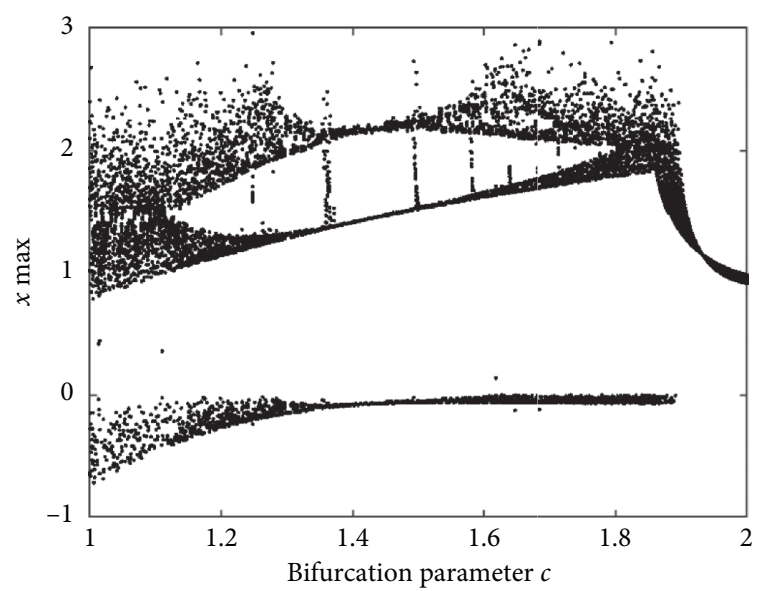

FIGURE 24: Bifurcation diagram with the variation of the parameter $c$. should be designed. Consider the driving fractional chaotic financial model provided by

$$
\begin{aligned}
& D_{c}^{\alpha} x_{1}=x_{3}+x_{2} x_{1}-a x_{1}, \\
& D_{c}^{\alpha} x_{2}=1-b x_{2}-x_{1}^{2}, \\
& D_{c}^{\alpha} x_{3}=-x_{1}-c x_{3} .
\end{aligned}
$$

Consider the response fractional chaotic financial model given by

$$
\begin{aligned}
& D_{c}^{\alpha} y_{1}=y_{3}+y_{2} y_{1}-a y_{1}+u_{1}, \\
& D_{c}^{\alpha} y_{2}=1-b y_{2}-y_{1}^{2}+u_{2}, \\
& D_{c}^{\alpha} y_{3}=-y_{1}-c y_{3}+u_{3},
\end{aligned}
$$

where the control $u=\left(u_{1}, u_{2}, u_{3}\right)$. We define the synchronization error described by the following forms:

$$
\begin{aligned}
& e_{1}=y_{1}-x_{1}, \\
& e_{2}=y_{2}-x_{2}, \\
& e_{3}=y_{3}-x_{3} .
\end{aligned}
$$

In this section, we provide a condition under which the control $u$ exists such that $\lim _{t \longrightarrow+\infty}\|e\|=\lim _{t \longrightarrow+\infty}$ $\|y-x\|=0$, where $e=\left(e_{1}, e_{2}, e_{3}\right), \quad x=\left(x_{1}, x_{2}, x_{3}\right)$, and $y=\left(y_{1}, y_{2}, y_{3}\right)$. We use the Lyapunov direct method to prove this statement. The following equation represents the fractional synchronization error system:

$$
\begin{aligned}
& D_{c}^{\alpha} e_{1}=e_{3}-a e_{1}+x_{1} e_{1}+y_{2} e_{1}+u_{1}, \\
& D_{c}^{\alpha} e_{1}=e_{3}-a e_{1}+x_{1} e_{1}+y_{2} e_{1}+u_{1}, \\
& D_{c}^{\alpha} e_{3}=-e_{1}-c e_{3}+u_{3} .
\end{aligned}
$$

We suppose the control design $u$ given by $u=\left(-x_{1} e_{1}-\right.$ $\left.y_{2} e_{1}, e_{1} x_{1}+e_{1} y_{1}, 0\right)$ and we choose the Lyapunov function defined by

$$
V\left(e_{1}, e_{2}, e_{3}\right)=e_{1}^{2}+e_{2}^{2}+e_{3}^{2} .
$$

The main idea is to utilize the stability condition applied to quadratic function given the relationship $D^{\alpha} e^{T} e \leq e^{T} D^{\alpha} e[35,37]$. The Caputo derivative along the trajectories of equations (68)-(70) is given by the following calculations:

$$
\begin{aligned}
D_{t}^{\kappa} V & \leq e_{1} D_{c}^{\alpha, \rho} e_{1}+e_{2} D_{c}^{\alpha} e_{2}+e_{3} D_{c}^{\alpha} e_{3} \\
& \leq e_{1}\left[e_{3}-a e_{1}\right]+e_{2}\left[-b e_{2}\right]+e_{3}\left[-e_{1}-c e_{3}\right] \\
& \leq-a e_{1}^{2}-b e_{2}^{2}-c e_{3}^{2} \\
& \leq-[a+b+c]\|e\|^{2} .
\end{aligned}
$$

Thus, under the supposed control, the trivial equilibrium of fractional synchronization error system is globally asymptotically stable, which in turn implies $\lim _{t \longrightarrow+\infty}\|e\|=\lim _{t \longrightarrow+\infty}\|y-x\|=0$. Finally, the signal feedback control $u$ synchronizes the financial chaotic system (10)-(12). 


\section{Stability Analysis, Bifurcation Diagram, and Lyapunov Exponent}

In this section, we analyze the dynamic behaviors of the fractional financial chaotic model, the stability analysis, the bifurcation diagram, and the Lyapunov exponent, explicitly. The stability analysis of the equilibrium points studies the asymptotic behavior of the solutions around the equilibrium point. The bifurcation concept will help us to quantify the sensitivity of the fractional financial model when one of the parameters of the model varies into a specific interval. At last, the Lyapunov exponent characterizes the existence of chaotic behavior. Note that when the Lyapunov exponent is large and positive, then we detect the presence of high chaos. In more simple terms, the Lyapunov exponent represents the average exponential ratio of the convergence between adjacent orbits of the nonlinear systems in the phase space.

In this section, we begin the investigations with the local stability analysis in the context of the fractional-order derivative. The classical method used to study the local stability with the Jacobian matrix is not the same as the method used in fractional context. In fractional context, we use the Matignon criterion [38]. The equilibrium point $x^{*}$ for the fractional differential equation $D_{t}^{\alpha} x=A x$ is said to be locally stable if only the following relationship is held [38]:

$$
|\arg (\lambda(A))|>\frac{\alpha \pi}{2} \text {. }
$$

The procedure in the local stability in the fractional context is presented in [39]. The method consists of calculating the Jacobian matrix in the context of integer-order derivative, calculating the characteristic polynomial with the standard method, and calculating the eigenvalues with the algebraic method, and we finish by testing all eigenvalues satisfying Matignon criterion (equation (73)) including the fractional order. First of all, the equilibrium points of the fractional financial equations (10)-(12) are obtained after solving the equations

$$
\begin{aligned}
& 0=z+y x-a x \\
& 0=1-b y-x^{2} \\
& 0=-x-c z
\end{aligned}
$$

and we obtain the following equilibrium points after calculations:

$$
\begin{aligned}
& E_{0}=\left(0, \frac{1}{b}, 0\right), \\
& E_{1}=\left(\sqrt{\frac{-b+c-a b c}{c}}, \frac{a c+1}{c},-\sqrt{\frac{-b+c-a b c}{c^{3}}}\right), \\
& E_{2}=\left(-\sqrt{\frac{-b+c-a b c}{c}}, \frac{a c+1}{c}, \sqrt{\frac{-b+c-a b c}{c^{3}}}\right) .
\end{aligned}
$$

For simplification, we directly take the values of the parameters used in the fractional financial chaotic model in Section 6 . We continue by considering the following values $a=0.9, b=0.2$, and $c=1.5$; thus $E_{0}=(0,5,0)$. The Jacobian matrix at the point $E_{0}$ is given by

$$
J=\left(\begin{array}{ccc}
4.1 & 0 & 1 \\
0 & -0.2 & 0 \\
-1 & 0 & -1.5
\end{array}\right) .
$$

The characteristic polynomial of the Jacobian matrix is represented after calculation in the following form:

$$
P(\lambda)=-\lambda^{3}+2.4 \lambda^{2}+5.67 \lambda+1.03
$$

The eigenvalues of the Jacobian matrix are given by $\lambda_{1}=-1.3, \lambda_{2}=-0.2$, and $\lambda_{3}=3.9$. We remark that $\left|\arg \left(\lambda_{1}\right)\right|=\pi />\alpha \pi / 2,\left|\arg \left(\lambda_{2}\right)\right|=\pi>\alpha \pi / 2$, and $\left|\arg \left(\lambda_{3}\right)\right|=$ $0<\alpha \pi / 2$. Thus, using the Matignon criterion in equation (73), we conclude that the equilibrium point $E_{0}$ is unstable.

We continue with the second equilibrium point $E_{1}=(0.8,1.6,-0.6)$. The Jacobian matrix at the point $E_{1}$ is given by

$$
J=\left(\begin{array}{ccc}
0.7 & 0.8 & 1 \\
-1.6 & -0.2 & 0 \\
-1 & 0 & -1.5
\end{array}\right)
$$

The characteristic polynomial of the Jacobian matrix is represented after calculation in the following form:

$$
P(\lambda)=-\lambda^{3}-\lambda^{2}-1.39 \lambda-1.91
$$

The eigenvalues of the Jacobian matrix are given by $\lambda_{1}=-1.1860, \quad \lambda_{2}=0.0929-1.2657 i, \quad$ and $\lambda_{3}=0.0929+$ 1.2657i. We remark that $\arg \left(\lambda_{1}\right)=\pi />\alpha \pi / 2, \arg \left(\lambda_{2}\right)=$ $274 \pi / 180>\alpha \pi / 2$, and $\arg \left(\lambda_{3}\right)=86 \pi / 180>\alpha \pi / 2$ when $\alpha<0.96$. Thus, using the Matignon criterion in equation (73), we conclude that the equilibrium point $E_{1}$ is locally stable if the order satisfies $\alpha<0.96$. The condition $\alpha<0.96$ justifies our choice related to $\alpha=0.95$. We finish by the equilibrium point $E_{2}=(-0.8,1.6,0.6)$. The Jacobian matrix at the point $E_{2}$ is given by

$$
J=\left(\begin{array}{ccc}
0.7 & -0.8 & 1 \\
1.6 & -0.2 & 0 \\
-1 & 0 & -1.5
\end{array}\right) .
$$

After checking, we remark that the rest of the calculations do not change. Thus the characteristic polynomial of the Jacobian matrix is given in the following form:

$$
P(\lambda)=-\lambda^{3}-\lambda^{2}-1.39 \lambda-1.91
$$

The eigenvalues of the Jacobian matrix are given by $\lambda_{1}=$ $-1.1860, \lambda_{2}=0.0929-1.2657 i$, and $\lambda_{3}=0.0929+1.2657 i$. We remark that $\left|\arg \left(\lambda_{1}\right)\right|=\pi />\alpha \pi / 2,\left|\arg \left(\lambda_{2}\right)\right|=274 \pi /$ $180>\alpha \pi / 2$., and $\left|\arg \left(\lambda_{3}\right)\right|=86 \pi / 180>\alpha \pi / 2$ when $\alpha<0.96$. Thus, using the Matignon criterion in equation (73), we conclude that the equilibrium point $E_{2}$ is locally stable if the order satisfies $\alpha<0.96$. The condition $\alpha<0.96$ justifies our choice related to $\alpha=0.95$ also.

To confirm the investigation in Section 6, we discuss the impact of the parameters using the bifurcation diagrams. 
In the first case, we suppose the saving amount $a=0.9$, the elasticity of demands $c=1.5$, and all other conditions in Section 6 are maintained. Still, we consider the per investment cost varies into the interval $b \in[0.1,0.3]$. The bifurcation diagram due to the variation of the per investment cost can be observed in Figure 22. That confirms as well the explanations in Section 6.

We continue with the bifurcation diagram obtained with the variation of the saving amount $a$. We fix the elasticity of demands $c=1.5$ and the per investment cost $b=0.2$; we consider the saving amount varies into the interval $a \in[0.1,1]$. The bifurcation diagram due to the variation of the saving amount can be observed in Figure 23. That confirms as well the explanations in Section 6.

We finish with the bifurcation diagram obtained with the variation of the elasticity of demands. We fix the saving amount $a=0.9$ and the per investment cost $c=0.2$; we consider the elasticity of demands varies into the interval $c \in[1,2]$. The bifurcation diagram due to the variation of the elasticity of demands can be observed in Figure 24. That confirms as well the explanations in Section 6.

In conclusion, we note very complex bifurcation generated by the variation of the parameters of the fractional financial chaotic system. In finance and economics, the complex bifurcation means we are in the context of recessions; in other words, we notice a significant decline in economic activities, and we particularly notice the increase in unemployment. The recession represents an economic situation during which the economy contracts. During this phase, all economic indicators are slowing down. This period is generally accompanied by a fall in salary and a fall in household purchasing power, thus causing a sharp drop in household consumption. In general, the predictions are very complicated to be made as can be observed with the diagram bifurcation in Figure 24.

At last, we finish with the Lyapunov exponent, whose role is to detect the existence of chaos. We give a brief investigation because the investigations related to the Lyapunov exponent for the fractional financial chaotic model can be found in [40]. We remind that, for the fractionalorder $\alpha=0.95$ and with $a=0.9, b=0.2$, and $c=1.5$, the maximum Lyapunov exponent at $t=110$ is given by $\mathrm{LE}_{\max }=0.0420$; the algorithm for getting the Lyapunov exponent in the context of fractional-order derivative can be found in [41]. Note that the numerical method used in [41] should be replaced by our numerical schemes proposed in this paper. We observe that the Lyapunov exponent given by $\mathrm{LE}_{\max }=0.0420$ is positive, which proves the existence of chaos as described in Section 6. We conclude that our investigations in Section 6 are confirmed by the maximal value of the Lyapunov exponent. The existence of chaos at $\alpha=0.95$ can also justify our choice related to the value of the fractional derivative.

\section{Conclusion}

A numerical method for the financial chaotic model has been discussed in the context of the fractional calculus. The impact of the saving amount, the per investment cost, and the elasticity of demands in the behaviors of the solution of the fractional financial chaotic model has been analyzed as well. The economical interpretations have been proposed for more understanding of the importance of these present investigations. For more understanding of the chaotic behavior of the chaotic financial model, the stability analysis of the equilibrium points, the bifurcation theory to analyze the impact of the parameters of the financial model carefully, and the Lyapunov exponent to detect the existence of the chaos have been discussed in this paper. For future work, it will be very interesting to study what will happen when the quadratic function $x^{2}$ is replaced by quadric function $x^{4}$ and what will be the maximal value of the Lyapunov exponent when chaos is detected. This problem is stated in the literature, but many questions are not solved. This paper supports the applications of fractional calculus in economics and finance. Future investigations can be developed in these directions.

\section{Data Availability}

No data were used to support this study.

\section{Conflicts of Interest}

The authors declare that they have no conflicts of interest.

\section{References}

[1] A. Chouchane-Verdier, "Une analyse empirique de l'impact de la libéralisation financière en Afrique subsaharienne sur la période 1983-1996," Revue Tiers Monde, vol. 179, no. 3, pp. 617-641, 2004.

[2] R. M. Solow, "A contribution to the theory of economic growth," The Quarterly Journal of Economics, vol. 70, no. 1, pp. 65-94, 1956.

[3] T. W. Swan, "Economic growth and capital accumulation," Economic Record, vol. 32, no. 2, pp. 334-361, 1956.

[4] R. E. Lucas, "On the mechanics of economic development," Journal of Monetary Economics, 1989.

[5] Turgot, "Paragon of the continental enlightenment," The Journal of Law and Economics, vol. 19, no. 3, pp. 607-619, 1976.

[6] G. J. Benston and C. W. Smith, "A transactions cost approach to the theory of financial intermediation," The Journal of Finance, vol. 31, no. 2, pp. 215-231, 1976.

[7] J. M. Keynes, "The general theory of employment, interest and money," The Collected Writings, vol. 7, pp. 1971-1979, Cambridge university Press, Cambridge, UK, 1964.

[8] E. D. Domar, "Expansion and employment," The American Economic Review, vol. 37, no. 1, pp. 34-55, 1947.

[9] M. Feldstein and J. H. Stock, "The use of a monetary aggregate to target nominal GDP," in Monetary Policy, pp. 7-69, The University of Chicago Press, Chicago, IL, USA, 1994.

[10] M. Obstfeld, How Integrated Are World Capital Markets? Some New Tests (No. W2075), National Bureau of Economic Research, Cambridge, MA, USA, 1986.

[11] R. Tobin, "The psychological significance of pubertal change," in Girls at Puberty, pp. 127-154, Springer, Boston, MA, USA, 1983.

[12] L. Dramani and O. Laye, Les Déterminants de L'investissement Privé au Sénégal: Une Approche VAR strucurel, Republique du Senegal, Ministere de l'Economie et des Finances, 2008. 
[13] J. L. Esso and Y. Keho, "The savings-investment relationship: cointegration and causality évidence from UEMOA countries," International Journal of Economics and Finance, vol. 2, no. 1, pp. 174-181, 2010.

[14] N. Dries and R. Pepermans, "How to identify leadership potential: development and testing of a consensus model," Human Resource Management, vol. 51, no. 3, pp. 361-385, 2012.

[15] A. Marshall, Principles of Economics, Mcmillan, London, UK, 8th edition, 1890.

[16] M. T. Shahiri, A. N. Ranjbar, R. Ghaderi, S. H. Hosseinnia, and S. Momani, "Control and synchronization of chaotic fractional-order coullet system via," Active Controller no. 2, 2012, https://arxiv.org/abs/1206.2415.

[17] B. Xin and Y. Li, "0-1 test for chaos in a fractional order financial system with investment incentive," Abstract and Applied Analysis, vol. 2013, p. 10, 2013.

[18] C. Chen, T. Fan, and B. Wang, "Inverse optimal control of hyperchaotic finance system," World Journal of Modelling and Simulation, vol. 10, no. 2, pp. 83-91, 2014.

[19] Q. Gao and J. Ma, "Chaos and Hopf bifurcation of a finance system," Nonlinear Dynamics, vol. 58, no. 1-2, pp. 209-216, 2009.

[20] D. Kumar and S. Kumar, "Construction of four dimensional chaotic finance model and its applications," International Journal of Pure and Applied Mathematics, vol. 118, no. 22, pp. 1171-1187, 2018.

[21] Y. Xu and Z. He, "Synchronization of variable order fractional financial system via active control method," Central European Journal Physics, vol. 11, no. 6, 2013.

[22] Z. Wang, X. Huang, and G. Shi, "Analysis of nonlinear dynamics and chaos in a fractional order financial system with time delay," Computers \& Mathematics with Applications, vol. 62, no. 3, pp. 1531-1539, 2011.

[23] W. Shaojie, H. Shaobo, A. Yousefpour, H. Jahanshahi, R. Repnik, and M. Perc, "Chaos and complexity in a fractional-order financial system with time delays," Chaos, Solitons Fractals, vol. 131, Article ID 109521, 2020.

[24] A. Akgul, C. Arslan, and B. Aricioglu, "Design of an Interface for random number Generators based on Integer and fractional order chaotic systems," Chaos, Theory and Applications, vol. 1, no. 1, pp. 1-18, 2019.

[25] K. Rajagopal, A. Akgul, S. Jafari, A. Karthikeyan, U. Cavusoglu, and S. Kacar, "An exponential jerk system, its fractional-order form with dynamical analysis and engineering application," Soft Computing, vol. 24, no. 10, pp. 7469-7479, 2020.

[26] J. Fahd, T. Abdeljawad, and D. Baleanu, "On the generalized fractional derivatives and their Caputo modification," The Journal of Nonlinear Sciences and Applications, vol. 10, no. 5, pp. 2607-2619, 2017.

[27] A. A. Kilbas, H. M. Srivastava, and J. J. Trujillo, Theory and Applications of Fractional Differential Equations, p. 204, North-Holland Mathematics Studies, Elsevier, Amsterdam, Netherlands, 2006.

[28] T. Mekkaoui, Z. Hammouch, D. Kumar, and J. Singh, “A new approximation scheme for solving ordinary differential equation with gomez-atangana-caputo fractional derivative," Methods of Mathematical Modelling, p. 51, CRC Press, Boca Raton, FL, USA, 2019.

[29] I. Podlubny, Fractional Differential Equations, Mathematics in Science and Engineering, p. 198, Academic Press, New York, NY, USA, 1999.
[30] N. Sene, "Integral balance methods for Stokes' first equation described by the left generalized fractional derivative," Physics, vol. 1, no. 1, pp. 154-166, 2019.

[31] N. Sene, "Second-grade fluid model with Caputo-Liouville generalized fractional derivative," Chaos, Solitons \& Fractals, vol. 133, p. 109631, 2020.

[32] N. Sene and A. N. Fall, "Homotopy perturbation $\rho$-laplace transform method and its application to the fractional diffusion equation and the fractional diffusion-reaction equation," Fractal and Fractional, vol. 3, no. 2, p. 14, 2019.

[33] N. Sene and A. Atangana, "Integral-balance methods for the fractional diffusion equation described by the caputo-generalized fractional derivative," Methods of Mathematical Modelling, p. 83, CRC Press, Boca Raton, FL, USA, 2019.

[34] N. Sene, "Stability analysis of the generalized fractional differential equations with and without exogenous inputs," Journal of Nonlinear Sciences and Applications, vol. 12, no. 9, pp. 562-572, 2019.

[35] N. Sene, "Global asymptotic stability of the fractional differential equations," Journal of Nonlinear Sciences and Applications, vol. 13, pp. 171-175, 2020.

[36] M. Yavuz, "Characterizations of two different fractional operators without singular kernel," Mathematical Modelling of Natural Phenomena, vol. 14, no. 3, p. 302, 2019.

[37] N. Sene, "Stability analysis of electrical RLC circuit described by the Caputo-Liouville generalized fractional derivative," Alexandria Engineering Journal, 2020.

[38] D. Matignon, "Stability results on fractional differential equations to control processing," in Proceedings of the Computational Engineering in Syatems and Application Multiconference; IMACS, vol. 2, pp. 963-968, Lille, France, 1996.

[39] E. Ahmed, A. M. A. El-Sayed, and H. A. A. El-Saka, "On some Routh-Hurwitz conditions for fractional order differential equations and their applications in Lorenz, Rössler, Chua and Chen systems," Physics Letters A, vol. 358, no. 1, pp. 1-4, 2006.

[40] W.-C. Chen, "Nonlinear dynamics and chaos in a fractionalorder financial system," Chaos, Solitons \& Fractals, vol. 36, no. 5, pp. 1305-1314, 2008.

[41] M.-F. Danca and N. Kuznetsov, "Matlab code for Lyapunov exponents of fractional-order systems," International Journal of Bifurcation and Chaos, vol. 28, no. 5, Article ID 1850067, 2018. 